\title{
Midterm clinical and echocardiographic results and predictors of mitral regurgitation recurrence following restrictive annuloplasty for ischemic cardiomyopathy
}

\author{
Francesco Onorati, MD, ${ }^{\mathrm{a}}$ Antonino S. Rubino, MD, ${ }^{\mathrm{a}}$ Domenico Marturano, MD, ${ }^{\mathrm{a}}$ Eugenia Pasceri, MD, ${ }^{\mathrm{b}}$ \\ Giuseppe Santarpino, MD, ${ }^{\mathrm{a}}$ Stefania Zinzi, MD ${ }^{\mathrm{b}}$ Giuseppina Mascaro, MD, ${ }^{\mathrm{b}}$ and Attilio Renzulli, MD, PhD, \\ FECTS $^{\mathrm{a}}$
}

\begin{abstract}
Objective: Although mitral restrictive annuloplasty plus coronary artery bypass grafting are considered the best therapeutic strategies for ischemic cardiomyopathy with chronic mitral regurgitation, some recurrences are still reported. We evaluated predictors for late recurrence of ischemic cardiomyopathy with chronic mitral regurgitation.
\end{abstract}

\begin{abstract}
Methods: Hospital outcome and serial clinical and echocardiographic (preoperative, discharge, 6 months, end of follow-up) follow-up assessments were recorded for 82 consecutive patients with ischemic cardiomyopathy with chronic mitral regurgitation having coronary artery bypass grafting + mitral restrictive annuloplasty ( 2 sizes ring downsizing). Recurrent ischemic cardiomyopathy with chronic mitral regurgitation was defined by grade $\geq 2$ at echocardiography.
\end{abstract}

Results: Hospital mortality was $4.9 \% ; 17.7 \pm 1.7$ (standard error) months (range $1-55$ ) survival was $95.5 \% \pm$ 2.5\%. Two-year Kaplan-Meier freedom from reintervention was $94.2 \% \pm 4.2 \%$; from rerevascularization, $87.5 \% \pm 11.7 \%$; from congestive heart failure, $83.8 \% \pm 5.7 \%$; from ischemic cardiomyopathy with chronic mitral regurgitation grade $\geq 2,46.5 \% \pm 11.2 \%$. Recurrence of ischemic cardiomyopathy with chronic mitral regurgitation gave lower 2-year Kaplan-Meier freedom from death $(P=.03)$ and lower 2-year freedom from congestive heart failure $(P=.0001)$, reintervention $(P=.034)$, and tricuspid insufficiency $(P=.0001)$. Ischemic cardiomyopathy with chronic mitral regurgitation recurrence correlated with worsened New York Heart Association class $(P=.0001)$, left ventricular ejection fraction $(P=.024)$, pulmonary arterial pressures $(P=.0001)$, left ventricular end-diastolic diameter $(P=.004)$, left ventricular end-systolic diameter $(P=.014)$, indexed left ventricular mass $(P=.008)$, and coaptation depth $(P=.0001)$. Independent predictors for recurrent ischemic cardiomyopathy with chronic mitral regurgitation were previous anterior + posterior myocardial infarction (odds ratio 3.70; confidence interval 2.93$5.41 ; P=.001$ ), preoperative left ventricular end-diastolic diameter $\geq 70 \mathrm{~mm}$ (odds ratio 3.91; confidence interval 2.65-5.22; $P=.001$ ), and coaptation depth at discharge $\geq 0.5 \mathrm{~cm}$ (odds ratio 11.9; confidence interval 5.91-21.34; $P=.0001)$. Preoperative left ventricular end-diastolic diameter $\geq 70 \mathrm{~mm}$ correlated with higher congestive heart failure $(P=.002)$, recurrent ischemic cardiomyopathy with chronic mitral regurgitation $(P=.0001)$, worsened New York Heart Association class $(P=.0001)$, and higher diuretics $(P=.0001)$. Coaptation depth $<0.5 \mathrm{~cm}$ at discharge accounted for better survival $(P=.010)$, lower incidence of congestive heart failure $(P=.0001)$, lower need for diuretics $(P=.0001)$, and improved New York Heart Association class $(P=.0001)$.

Conclusions: Failure of mitral restrictive annuloplasty is responsible for follow-up mortality and congestive heart failure and correlates with absence of cardiac reverse remodeling. Prognosis of patients having mitral restrictive annuloplasty for ischemic cardiomyopathy with chronic mitral regurgitation is good, as long as a low postoperative coaptation depth is achieved. Patients with significant left ventricular dilation should be considered for different surgical strategies.

Different animal and human studies suggested that pathogenesis of ischemic chronic mitral regurgitation (ICMR) is complex and is related to geometrical alterations of the left

From the Cardiac Surgery Unit ${ }^{\mathrm{a}}$ and the Cardiology Unit, ${ }^{\mathrm{b}}$ Magna Graecia University of Catanzaro, Catanzaro, Italy.

Received for publication Oct 16, 2008; revisions received Dec 18, 2008; accepted for publication Jan 24, 2009; available ahead of print April 9, 2009.

Address for reprints: Francesco Onorati, MD, Viale dei Pini, 28, 80131 Napoli, Italy (E-mail: frankono@libero.it).

J Thorac Cardiovasc Surg 2009;138:654-62

$0022-5223 / \$ 36.00$

Copyright (c) 2009 by The American Association for Thoracic Surgery doi: $10.1016 /$ j.jtcvs. 2009.01 .020 ventricle and of the apparatus of the mitral valve (MV). ${ }^{1-3}$ In particular, left ventricular sphericalization, annular enlargement, increased tenting area, and loss of systolic mitral annular contraction all contribute to the development of ICMR. ${ }^{4}$ As ICMR results from multiple mechanisms, current surgical therapy consisting of mitral restrictive annuloplasty (MRA) with an undersized annular ring does not always provide durable repair. ${ }^{4}$

Different preoperative echocardiographic predictors of ICMR recurrence have been described, ranging from ventricular dilation, ${ }^{5}$ high sphericity index, ${ }^{6}$ high interpapillary 


$$
\begin{array}{ll}
\text { Abbreviations and Acronyms } \\
\text { AMI }=\text { acute myocardial infarction } \\
\text { CABG }=\text { coronary artery bypass grafting } \\
\text { CD } & =\text { coaptation depth } \\
\text { CHF } & =\text { congestive heart failure } \\
\text { CPB } & =\text { cardiopulmonary bypass } \\
\text { ICMR } & =\text { ischemic chronic mitral regurgitation } \\
\text { LAD } & =\text { left atrial diameter } \\
\text { LVEDD } & =\text { left ventricular end-diastolic diameter } \\
\text { LVEF } & =\text { left ventricular ejection fraction } \\
\text { LVESD } & =\text { left ventricular end-systolic diameter } \\
\text { LVMi } & =\text { indexed left ventricular mass } \\
\text { mean } \Delta p & =\text { transmitral mean gradient } \\
\text { MRA } & =\text { mitral restrictive annuloplasty } \\
\text { MV } & =\text { mitral valve } \\
\text { NYHA } & =\text { New York Heart Association } \\
\text { PAP } & =\text { systolic pulmonary arterial pressure } \\
\text { TI } & =\text { tricuspid insufficiency grading }
\end{array}
$$

distance, ${ }^{7}$ coaptation depth $(\mathrm{CD})>10 \mathrm{~mm} .{ }^{8}$ All these data suggest that surgery cannot effectively induce reverse remodeling of severely impaired ventricles. Accordingly, recurrence of ICMR has been predominantly related to progressive ventricular remodeling. Similarly, when MRA fails, recurrent episodes of heart failure occur and followup morbidity and mortality increase. ${ }^{9}$ However, literature still lacks intraoperative or postoperative indexes anticipating MRA failure.

Therefore, it was the aim of the study to rule out independent predictors of recurrent ICMR following MRA. Echocardiographic and clinical outcomes in patients with successful MRA or with MRA failure were also compared.

\section{MATERIALS AND METHODS \\ Patients and Surgery}

Between August 2004 and February 2008, 84 nonselected consecutive patients admitted because of coronary disease and ICMR, having MRA+ coronary artery bypass grafting (CABG), were enrolled in the study. Our Institutional Review Board approved this study and waived the need for individual consent. All patients had ICMR grade $3+$ or $4+$ at preoperative echocardiography. Patients demonstrating ICMR grade $2+$ had intraoperative provocative testing and were enrolled whenever $3+$ to $4+$ ICMR was evidenced. ICMR was always due to postinfarction restrictive systolic leaflet motion (Carpentier type IIIb), to severe annular dilation because of ischemic dilated cardiomyopathy (Carpentier type I), or to a combination of both (Carpentier type I+IIIb; Table 1). Patients with concomitant surgical procedures (apart from tricuspid annuloplasty) were excluded. Accordingly, patients with tricuspid regurgitation grade $\geq 2$ or tricuspid regurgitation $<2+$ in the presence of dilated tricuspid annulus exceeding $21 \mathrm{~mm} / \mathrm{m}^{2}$ indexed to body surface area at transthoracic echocardiography always had tricuspid annuloplasty.

All patients had symptoms of heart failure, and the majority presented in New York Heart Association (NYHA) class III or IV (Table 1). Both elective and nonelective patients were enrolled. Mean logistic European System for Cardiac Operative Risk Evaluation (EuroSCORE) was $8.3 \pm 1.5$. Baseline characteristics are presented in Table 1.
TABLE 1. Preoperative and intraoperative data

\begin{tabular}{lcc}
\hline \multicolumn{1}{c}{ Variables } & No. of patients & $\begin{array}{c}\text { \% of global } \\
\text { population }\end{array}$ \\
\hline Age (y) & $70.2 \pm 3.8$ & - \\
Sex (male) & 54 & 65.8 \\
EUROscore & $8.3 \pm 1.5$ & - \\
NYHA class & $3.4 \pm 0.6$ & - \\
Canadian Class Score & $3.3 \pm 0.8$ & - \\
Diabetes & 36 & 43.9 \\
Hypertension & 55 & 67.0 \\
COPD & 25 & 30.5 \\
Left main stem disease & 26 & 31.7 \\
Previous AMI & 51 & 62.2 \\
Recent (<4 wk) AMI & 42 & 51.2 \\
Anterior AMI & 10 & 12.1 \\
Posterior AMI & 57 & 69.5 \\
Anterior + posterior AMI & 11 & 13.4 \\
Emergency & 3 & 3.6 \\
UA/NSTEMI & 31 & 37.8 \\
STEMI & 1 & 1.2 \\
No. CABG & $2.4 \pm 0.9$ & - \\
LITA CABG & 82 & 100 \\
Radial artery CABG & 24 & 29.3 \\
ACC time & $73.6 \pm 4.5$ & - \\
CPB time & $126.9 \pm 12.2$ & - \\
Tricuspid plasty & 21 & \\
& & \\
& &
\end{tabular}

\section{CABG}

Mean flow (mL/min) Pulsatility index

\begin{tabular}{lll}
\hline $\begin{array}{l}\text { LITA-to-left anterior } \\
\text { descending }\end{array}$ & $38.6 \pm 18.2$ & $1.5 \pm 1.0$ \\
Radial artery & $44.7 \pm 27.1$ & $1.1 \pm 0.9$ \\
Saphenous vein & $38.4 \pm 12.2$ & $1.8 \pm 1.1$
\end{tabular}

COPD, Chronic obstructive pulmonary disease; EuroSCORE, European System for Cardiac Operative Risk Evaluation; AMI, acute myocardial infarction; UA/NSTEMI, unstable angina/non-ST elevation myocardial infarction; $C A B G$, coronary artery bypass graft; $L I T A$, left internal thoracic artery; $A C C$, aortic crossclamp; $C P B$, cardiopulmonary bypass.

Surgery was performed by the same surgeon (A.R.) through a median sternotomy. The ascending aorta was always cannulated, and the venous return was always accomplished through a double caval cannulation. CABG was constructed as already reported. ${ }^{10}$ The mitral valve was exposed through longitudinal atriotomy along the Waterston's groove in all patients. Ring size (Carpentier-Edwards Physio ringor Carpentier-McCarthy-Adams ring; both Edwards LifeSciences, Irving, Calif) was determined after measurement of the height of the anterior leaflet and intertrigonal distance, and then downsizing by 2 sizes (ie, size 26 when measuring 30). Complete symmetric rings (Carpentier-Edwards Physio rings) were preferred when ICMR was predominantly due to annular dilation (Carpentier type I), and complete asymmetric rings (Carpentier-McCarthy-Adams rings) were used when inferior or posterolateral infarction caused restrictive systolic leaflet motion (Carpentier type IIIb). Tricuspid annuloplasty was always accomplished with a Carpentier Edwards MC3 ring (Edwards Lifesciences). Cardiopulmonary bypass (CPB) was standardized and conducted as already reported. $^{10}$

\section{Echocardiography}

Echocardiography was always performed by the same 2 cardiologists, blinded toward the surgical technique, using a VIVID 7 Pro ultrasound machine (GE Technologies, Milwaukee, Wis). All patients had transthoracic 
echocardiography preoperatively, at hospital discharge, at 6 months' follow-up, and at the end of the follow-up (mean $17.8 \pm 15.3$ [standard deviation] months; range 1-55 months). Follow-up was closed on March 30,2008 and was $100 \%$ completed.

Transthoracic echocardiographic evaluation consisted of standard echocardiography examination, including grading of the severity of ICMR (semiquantitatively from color-flow Doppler), left atrial diameter (LAD), left ventricular end-diastolic diameter (LVEDD), left ventricular end-systolic diameter (LVESD), left ventricular ejection fraction (LVEF), indexed left ventricular mass (LVMi), CD, transmitral mean gradient (mean $\Delta \mathrm{p}$ ), systolic pulmonary arterial pressure (PAP), and tricuspid insufficiency grading $(\mathrm{TI})$.

All patients also had intraoperative transesophageal echocardiography assessment of left ventricular and valve function. MV repair was considered successful if there was no residual mitral regurgitation following CPB discontinuation, with an adequate preload achieved (central venous pressure between 10 and $15 \mathrm{~mm} \mathrm{Hg}$ ). Recurrence of ICMR was defined as grade $\geq 2+/ 4+$ at semiquantitative color-flow Doppler analysis.

\section{Clinical Assessment and Follow-up}

Preoperative clinical status was determined according to the criteria of the NYHA up to 5 days before surgery and was reassessed at discharge, at 6 months, and at the end of follow-up. As a surrogate outcome of heart failure, need and dose of furosemide were assessed at the same time points. Deaths and episodes of acute congestive heart failure (CHF), redo mitral surgery, and re-revascularization (either surgical or percutaneous) during the follow-up were recorded.

\section{Statistical Analysis}

All data were prospectively recorded using the institutional database. Statistical analysis was performed by the SPSS program for Windows, version 13.0 (SPSS Inc, Chicago, Ill). Continuous variables are presented as mean \pm standard deviation, and categorical variables are presented as absolute numbers and percentages. Data were checked for normality before statistical analysis. Normally distributed continuous variables were compared using the unpaired $t$ test, whereas the Mann-Whitney $U$ test was used for non-normally distributed variables. Categorical variables were analyzed using either the chi-square test or Fischer exact test. Comparisons between and within groups were made using 2-way analysis of variance for repeated measures. Univariate analyses of risk factors for recurrence of ICMR were performed, calculating odds ratios with $95 \%$ confidence intervals. Variables with a $P$ value $<.0001$ were consecutively subjected to a multivariate logistic regression model to assess the independent impact of each risk factor on recurrence of ICMR. A stepwise (backward Wald) multivariable binary logistic regression analysis was used to test for predictors of recurrence of ICMR. Both regression model discrimination and calibration were assessed by using the c-statistic for regression model discrimination and the Hosmer-Lemeshow test statistic for model calibration.

Two-year freedoms from death, CHF, hospital readmission, and redo surgery were determined with the method of Kaplan-Meier life table analysis. Log-rank test was performed to ascertain differences between patients with and without ICMR recurrence.

\section{RESULTS}

Preoperative and intraoperative data are reported in Table 1.

\section{Intraoperative Mitral Results}

During the study period, 2 patients demonstrated persistent intraoperative 1 to $2+$ ICMR following CPB despite 2-size undersizing and had valve replacement following reestablishment of CPB. Therefore, these 2 patients were excluded from the study because of the different surgical therapy. The remaining 82 patients achieved a successful MV repair and were definitively enrolled and followed. Mean mitral ring size was $25.7 \pm 1.8$ (median size 26; range 24-32). There were no cases of systolic anterior motion or significant mitral stenosis (mean transvalvular gradient 4.5 $\pm 0.5 \mathrm{~mm} \mathrm{Hg}$; mean MV area $2.7 \pm 1.0 \mathrm{~cm}^{2}$ ). Twentynine patients $(35.3 \%)$ had tricuspid annuloplasty. Transittime flowmetry demonstrated good values in all CABG (Table 1).

\section{Hospital Outcome}

Hospital mortality was $4.9 \%$ (4 patients). There were 1 perioperative acute myocardial infarction (AMI; $1.2 \%$ ) and 5 postoperative low output state $(6.1 \%)$ requiring prolonged intra-aortic balloon pump ( $>48$ hours) and inotropic support with intravenous dobutamine and levosimendan; transient paroxysmal atrial fibrillation requiring intravenous amiodarone developed in 18 patients $(21.9 \%)$. Three patients $(3.6 \%)$ experienced respiratory failure because of pneumonia, acute renal failure requiring renal replacement therapy with continuous venovenous hemofiltration developed in 2 patients $(2.4 \%)$, and cognitive dysfunction developed in 1 patient $(1.2 \%)$. Overall hospital morbidity accounted for 22 patients $(26.8 \%)$. Intensive care stay was $43.4 \pm 9.1$ hours (range 28-84 hours); hospital stay was $6.7 \pm 2.4$ days. However, excluding the 4 patients who died, all other patients completely recovered and were discharged in healthy conditions.

\section{Follow-up Clinical Outcome}

Mean follow-up was $17.8 \pm 1.7$ (standard error) months (range 1-55 months). Three patients died during follow-up because of acute $\mathrm{CHF}(\mathrm{n}=2)$ and sudden death $(\mathrm{n}=1)$. Both patients who died of CHF showed recurrence of ICMR at follow-up. Therefore, the 2-year Kaplan-Meier freedom from death was $96.5 \% \pm 2.5 \%$ (Figure 1, A). CHF developed in 9 patients during follow-up (2-year actuarial freedom from CHF $83.0 \% \pm 5.7 \%$; Figure 1,B), 2 patients needed redo mitral surgery (2-year actuarial freedom from mitral reintervention $94.2 \% \pm 4.2 \%$; Figure $1, C$ ), and 1 patient had re-revascularization (2-year actuarial freedom from re-revascularization $87.5 \% \pm 11.7 \%$ ).

Twenty patients $(25.6 \%)$ of 78 discharged from the hospital had recurrent ICMR (grade $\geq 2$ ) at echocardiographic follow-up, resulting in a 2-year actuarial freedom from ICMR of $46.5 \% \pm 11.2 \%$ (Figure $1, D$ ). However, when patients with recurrent ICMR were compared with those without ICMR, a significantly lower 2-year freedom from death (log-rank $P=.0001$; Figure $2, A$ ), from CHF (logrank $P=.030$; Figure $2, B$ ), and from redo mitral surgery $(P=.034$; Figure $2, C)$ was demonstrated. Moreover, a significant proportion of patients with preoperative severe 
Survival Function

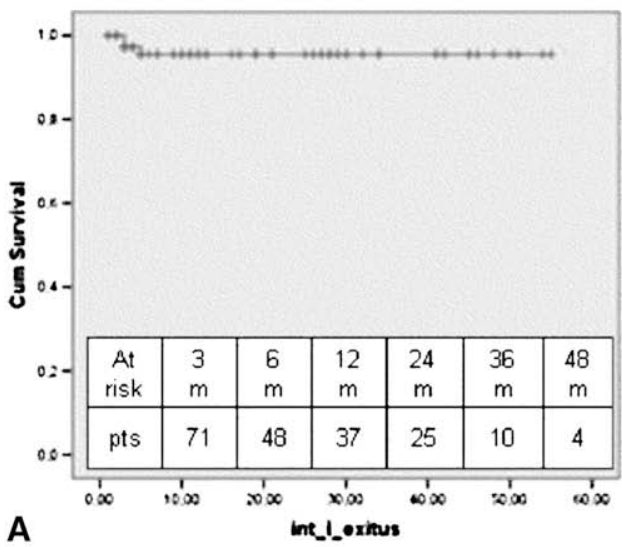

Survival Function

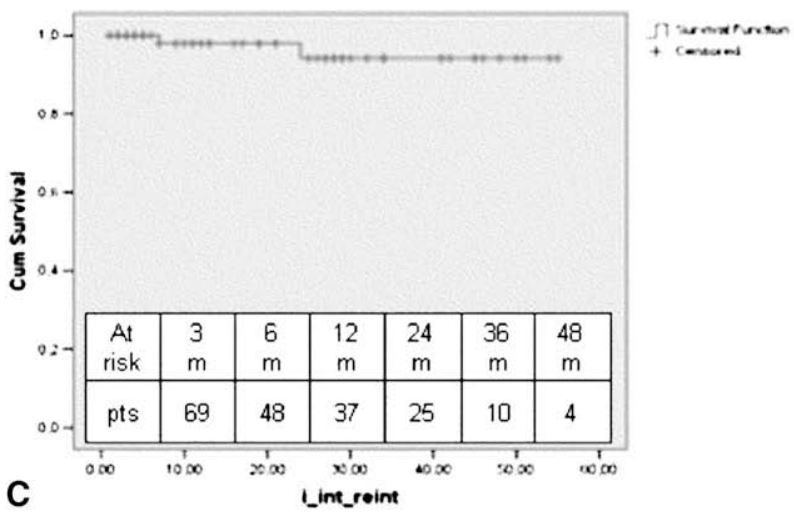

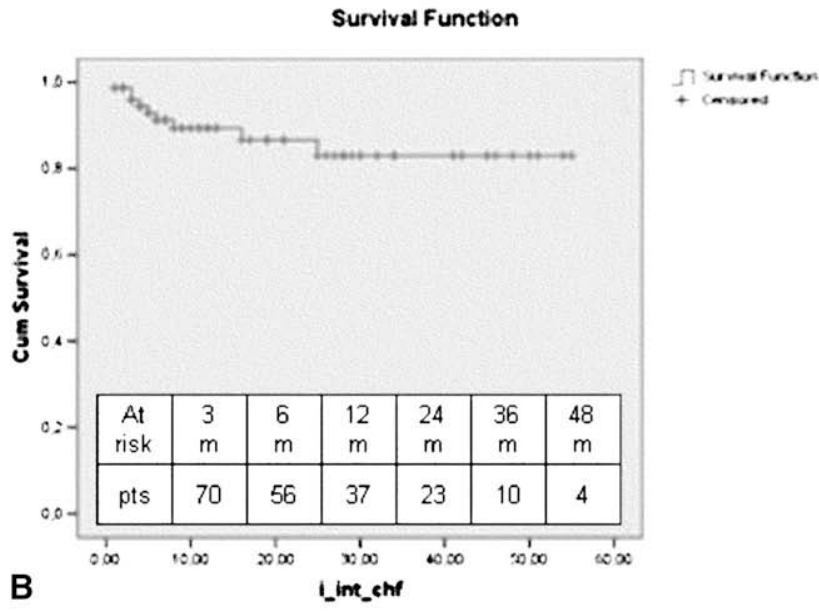

Survival Function

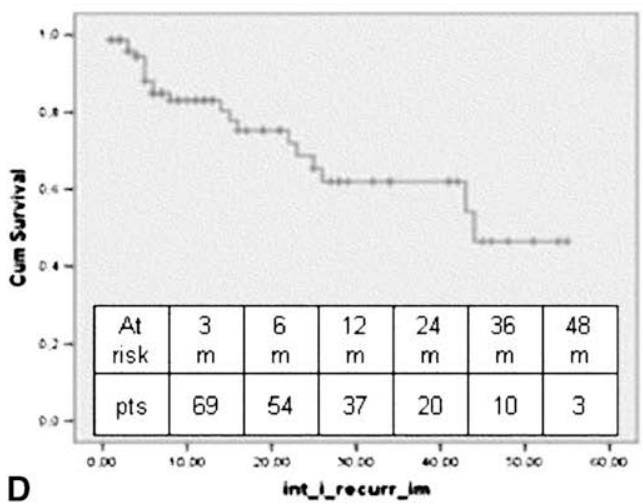

FIGURE 1. Actuarial survival (A) and freedom from congestive heart failure (B), redo mitral surgery (C), re-revascularization (D).

systolic impairment (LVEF $<25 \% ; 8$ patients $[9.7 \%$ of the population]) had recurrent ICMR following surgery (recurrent ICMR 6/20 [30.0\%] vs no recurrent ICMR 2/62 $[3.2 \%$ ]; $P=.002$ ).

When functional status was considered, despite the fact that both groups of patients (those with recurrent ICMR or not) improved their NYHA class, those without ICMR during follow-up showed a significantly better recovery of NYHA class, together with a significantly lower need for diuretics (Table 2). Accordingly, recurrent ICMR induced progressive increase of the daily furosemide during the follow-up (Table 2).

\section{Echocardiographic Results}

A completely different pattern of left and right ventricular echocardiographic results was found in patients with recurrent ICMR and those without ICMR. In particular, patients with recurrent ICMR showed absence of reverse remodeling of LVEDD, LVESD, and LVMi, with a slight augmentation of LAD (Table 3). Accordingly, LVEF did not improve during the follow-up despite revascularization. TI grade and PAP did not decrease despite MRA-reduced ICMR
(Table 3). MRA might have mimicked iatrogenic mild stenosis, given the slight augmentation of the transmitral mean $\Delta \mathrm{p}$. Finally, after a significant amelioration of mitral $\mathrm{CD}$ at discharge, $\mathrm{CD}$ increased parallel to the worsening of ICMR, transmitral mean $\Delta \mathrm{p}$ progressive reduced, and PAP and TI worsened (Table 3).

On the other hand, patients without recurrent ICMR during the follow-up correlated with a significant reverse remodeling of LVEDD, LVESD, LVMi, together with the improvement of LVEF (Table 3). These same patients demonstrated persistently shortened CD from discharge to the end of follow-up and showed a higher mean $\Delta \mathrm{p}$ (compared with patients with recurrent ICMR), with absence of LAD reverse remodeling (Table 3). In this group of patients, TI grade and PAP were reduced in parallel (Table 3 ).

\section{Predictors of MRA Failure}

Univariate analysis revealed that 23 of 45 recorded variables had a significant $(P<.05)$ association with recurrence of ICMR during the follow-up (see Appendix). Stepwise logistic regression analysis revealed 3 variables as independent predictors of ICMR recurrence: previous 

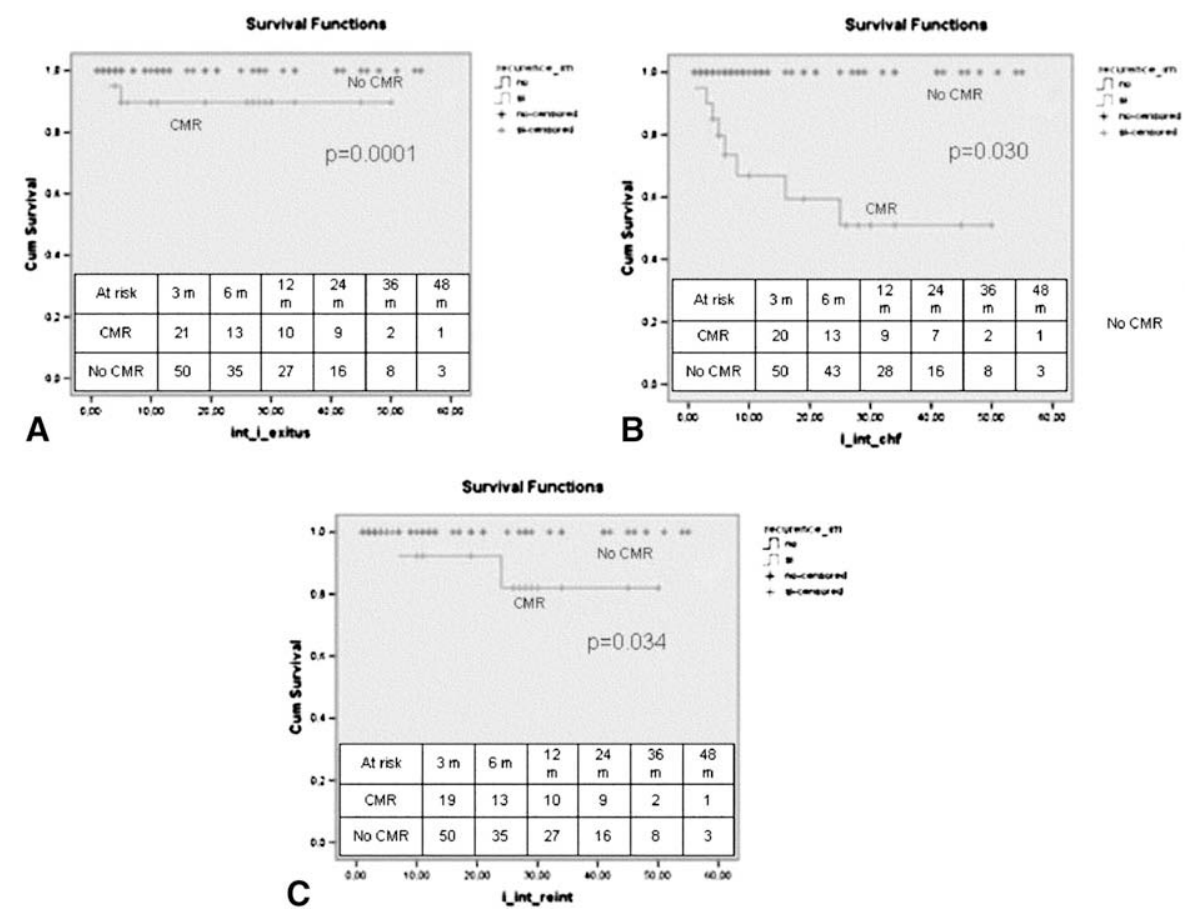

FIGURE 2. Survival (A), freedom from congestive heart failure (B), and mitral reintervention (C) between patients with ischemic chronic mitral regurgitation recurrence and those without ischemic chronic mitral regurgitation recurrence.

anterior + posterior myocardial infarction (odds ratio 3.70), preoperative LVEDD $\geq 70 \mathrm{~mm}$ (odds ratio 3.91), and CD at discharge $\geq 0.5 \mathrm{~cm}$ (odds ratio 11.9; Table 4). The discrimination

c-statistic for the final logistic regression analysis was 0.950 , suggesting that about $95 \%$ of the time, the model predicted a correct response given a set of positive predictor variables. The chi-square test result for the Hosmer-Lemeshow test was 5.11 with 7 degrees of freedom, for an overall chisquare significance of 0.646 .

\section{Stratification According to Postoperative CD $<0.5$ $\mathrm{cm}$ and LVEDD $\geq 70 \mathrm{~mm}$}

Subgroup analysis of patients stratified according to discharge $\mathrm{CD} \geq 0.5 \mathrm{~cm}$ or $\mathrm{CD}<0.5 \mathrm{~cm}$ revealed significant differences in terms of major clinical end points. In particular, patients with $\mathrm{CD}<0.5 \mathrm{~cm}$ at discharge showed better survival (log-rank $P=.010$; Figure 3, $A$ ) and higher 2-year freedom from CHF (log-rank $P=.0001$; Figure 3, $B$ ). Accordingly, patients with $\mathrm{CD}<0.5 \mathrm{~cm}$ demonstrated significantly better NYHA class during the postoperative and follow-up timecourse (between-groups $P=.0001$ ), with lower need for daily furosemide (between-groups $P=.0001$; Table 5).

Similarly, when patients were dichotomized according to the preoperative left ventricular dilation, those with preoperative LVEDD $\geq 70 \mathrm{~mm}$ showed a significantly lower 2-year freedom from recurrent ICMR $(10.3 \% \pm 9.4 \%$ vs LVEDD $<70 \mathrm{~mm} 77.3 \% \pm 13.1 \% ; P=.0001)$, with lower 2-year freedom from CHF $(53.9 \% \pm 15.6 \%$ vs LVEDD $<70$ $\mathrm{mm} 94.1 \% \pm 3.3 \%, P=.002)$. Furthermore, LVEDD $\geq$ $70 \mathrm{~mm}$ correlated with a progressive worsening of NYHA class during the follow-up (between-groups $P=.0001$ ), which paralleled a progressive increase of the daily diuretic dose (between-groups $P=.0001$, Table 5).

TABLE 2. Recovery of NYHA class and need for daily dose of diuretics in patients with and without ICMR recurrence

\begin{tabular}{lcccccc}
\hline & Preoperative NYHA & Discharge NYHA & 6-mo NYHA & Follow-up NYHA & $\boldsymbol{P}^{*}$ & $\boldsymbol{P}_{\dagger}$ \\
\hline ICMR & $3.7 \pm 0.4$ & $1.8 \pm 0.3$ & $2.1 \pm 0.6$ & $2.6 \pm 0.7$ & .0001 & .0001 \\
No ICMR & $3.2 \pm 0.5$ & $1.5 \pm 0.5$ & $1.3 \pm 0.4$ & $1.0 \pm 0.1$ & .0001 \\
& Preoperative daily & Discharge daily & 6-mo daily & Follow-up daily & & \\
& furosemide (mg) & furosemide (mg) & furosemide (mg) & furosemide (mg) & $\boldsymbol{P}^{*}$ & $\boldsymbol{P}_{\dagger}$ \\
\hline ICMR & $92.2 \pm 45.7$ & $42.3 \pm 13.6$ & $59.4 \pm 28.4$ & $82.1 \pm 28.5$ & .05 & .0001 \\
No ICMR & $71.5 \pm 23.4$ & $25.5 \pm 14.2$ & $20.2 \pm 11.2$ & $13.2 \pm 8.5$ & .0001 & \\
\hline
\end{tabular}

ICMR, Ischemic chronic mitral regurgitation; NYHA, New York Heart Association. *Statistical probability within group; †statistical probability between groups. 
TABLE 3. Echocardiographic results

\begin{tabular}{|c|c|c|c|c|c|c|}
\hline & Preoperative ICMR & Discharge ICMR & 6-mo ICMR & Follow-up ICMR & $P^{*}$ & $\boldsymbol{P} \dagger$ \\
\hline ICMR & $3.5 \pm 0.6$ & $1.2 \pm 0.4$ & $1.8 \pm 0.4$ & $2.5 \pm 0.5$ & .209 & .0001 \\
\hline \multirow[t]{2}{*}{ No ICMR } & $3.4 \pm 0.5$ & $0.7 \pm 0.4$ & $0.6 \pm 0.4$ & $0.5 \pm 0.5$ & .0001 & \\
\hline & Preoperative LAD & Discharge LAD & 6-mo LAD & Follow-up LAD & $P^{*}$ & $\boldsymbol{P} \dagger$ \\
\hline ICMR & $46.1 \pm 5.7$ & $46.3 \pm 5.9$ & $46.9 \pm 5.5$ & $46.1 \pm 10.6$ & .301 & .101 \\
\hline \multirow[t]{2}{*}{ No ICMR } & $45.6 \pm 3.4$ & $45.5 \pm 3.2$ & $44.7 \pm 3.6$ & $44.3 \pm 3.8$ & .063 & \\
\hline & Preoperative LVEDD & Discharge LVEDD & 6-mo LVEDD & Follow-up LVEDD & $P^{*}$ & $\boldsymbol{P} \dagger$ \\
\hline ICMR & $67.1 \pm 8.2$ & $67.0 \pm 8.0$ & $67.6 \pm 8.2$ & $67.7 \pm 8.0$ & .282 & .004 \\
\hline \multirow[t]{2}{*}{ No ICMR } & $63.9 \pm 4.9$ & $62.4 \pm 4.9$ & $61.4 \pm 4.8$ & $60.5 \pm 5.2$ & .0001 & \\
\hline & Preoperative LVESD & Discharge LVESD & 6-mo LVESD & Follow-up LVESD & $P^{*}$ & $\boldsymbol{P} \dagger$ \\
\hline ICMR & $55.3 \pm 13.5$ & $55.3 \pm 13.0$ & $55.3 \pm 13.6$ & $55.4 \pm 13.3$ & .773 & .014 \\
\hline \multirow[t]{2}{*}{ No ICMR } & $54.4 \pm 6.6$ & $49.6 \pm 6.6$ & $48.1 \pm 6.4$ & $46.8 \pm 5.9$ & .0001 & \\
\hline & Preoperative LVMi & Discharge LVMi & 6-mo LVMi & Follow-up LVMi & $P^{*}$ & $\boldsymbol{P} \dagger$ \\
\hline ICMR & $145.3 \pm 19.2$ & $145.4 \pm 19.5$ & $145.8 \pm 20.2$ & $146.2 \pm 19.1$ & .089 & .008 \\
\hline \multirow[t]{2}{*}{ No ICMR } & $138.7 \pm 20.2$ & $138.5 \pm 19.9$ & $136.2 \pm 19.6$ & $134.6 \pm 19.3$ & .002 & \\
\hline & Preoperative LVEF & Discharge LVEF & 6-mo LVEF & Follow-up LVEF & $P^{*}$ & $\boldsymbol{P} \dagger$ \\
\hline ICMR & $38.1 \pm 8.7$ & $35.2 \pm 8.0$ & $36.1 \pm 9.7$ & $36.3 \pm 8.9$ & .713 & .024 \\
\hline \multirow[t]{2}{*}{ No ICMR } & $40.1 \pm 6.8$ & $37.8 \pm 6.9$ & $42.7 \pm 6.8$ & $44.9 \pm 7.2$ & .0001 & \\
\hline & Preoperative CD & Discharge CD & 6-mo CD & Follow-up CD & $P^{*}$ & $\boldsymbol{P} \dagger$ \\
\hline ICMR & $1.3 \pm 0.2$ & $0.7 \pm 0.3$ & $0.8 \pm 0.4$ & $0.8 \pm 0.4$ & .001 & .0001 \\
\hline \multirow[t]{2}{*}{ No ICMR } & $1.3 \pm 0.2$ & $0.4 \pm 0.2$ & $0.4 \pm 0.1$ & $0.5 \pm 0.2$ & .0001 & \\
\hline & Preoperative mean $\Delta \mathrm{p}$ & Discharge mean $\Delta p$ & 6-mo mean $\Delta p$ & Follow-up mean $\Delta p$ & $\boldsymbol{P}^{*}$ & $\boldsymbol{P} \dagger$ \\
\hline ICMR & $0.9 \pm 0.9$ & $4.7 \pm 0.9$ & $4.3 \pm 0.8$ & $3.9 \pm 1.1$ & .001 & .0001 \\
\hline \multirow[t]{2}{*}{ No ICMR } & $0.9 \pm 0.8$ & $5.6 \pm 1.3$ & $5.7 \pm 1.2$ & $5.8 \pm 1.3$ & .0001 & \\
\hline & Preoperative TI & Discharge TI & 6-mo TI & Follow-up TI & $P^{*}$ & $\boldsymbol{P} \dagger$ \\
\hline ICMR & $2.1 \pm 0.6$ & $1.3 \pm 0.5$ & $1.5 \pm 0.6$ & $2.0 \pm 0.7$ & .544 & .0001 \\
\hline \multirow[t]{2}{*}{ No ICMR } & $1.9 \pm 0.5$ & $1.1 \pm 0.2$ & $1.1 \pm 0.2$ & $1.1 \pm 0.4$ & .0001 & \\
\hline & Preoperative PAP & Discharge PAP & 6-mo PAP & Follow-up PAP & $P^{*}$ & $\boldsymbol{P} \dagger$ \\
\hline ICMR & $45.0 \pm 8.4$ & $36.6 \pm 7.9$ & $39.1 \pm 8.7$ & $38.6 \pm 10.2$ & .110 & .0001 \\
\hline No ICMR & $38.1 \pm 6.4$ & $31.3 \pm 5.9$ & $29.6 \pm 5.5$ & $28.8 \pm 5.6$ & .0001 & \\
\hline
\end{tabular}

$I C M R$, Ischemic chronic mitral regurgitation; $L A D$, left atrial diameter; $L V E D D$, left ventricular diastolic diameter; $L V E S D$, left ventricular systolic diameter; $L V M i$, left ventricular mass index; $L V E F$, left ventricular ejection fraction; $C D$, coaptation depth; $\triangle p$, pressure gradient; $T I$, tricuspid insufficiency; $P A P$, pulmonary arterial pressure systolic. $*$ Statistical probability within group; †statistical probability between groups.

\section{DISCUSSION}

ICMR is considered a common cause of post-AMI congestive heart failure, and it is present in $10 \%$ to $20 \%$ of patients with coronary artery disease. ${ }^{11}$ Moreover, it has been considered one of the few targets for therapeutic opportunities in heart failure. ${ }^{11}$ According to the complex and different pathogenetic mechanisms underlying such disease, a number of different surgical techniques have been developed for ICMR..$^{1-4,11}$ Of all the procedures described, MRA proved to be effective, safe, and reproducible. ${ }^{5-9,11}$ However, all these experiences reported some recurrences, ranging from $15 \%$ to $30 \%$, because of a different population profile and follow-up. ${ }^{5,7,8,11}$ In our series, 20 patients (25.6\%) had MRA failure during follow-up, in line with other reports. Moreover, a recent article, examining 585 patients over a 17 -year period, found that recurrences developed in $28 \%$ of patients at 6 months. ${ }^{12}$

The main cause of early failure seems consequential to the action of MRA only at the annular level, whereas it does not fully address the ventricular causes of ICMR. ${ }^{11,12}$ Therefore,

TABLE 4. Independent predictors of recurrence of ICMR analyzed by multivariate logistic regression analysis

\begin{tabular}{lccc}
\hline \multicolumn{1}{c}{ Variables } & $\begin{array}{c}\text { Odds } \\
\text { ratio }\end{array}$ & $\begin{array}{c}\text { Confidence } \\
\text { limit }(\mathbf{9 5} \%)\end{array}$ & $\boldsymbol{P}$ \\
\hline Anterior + posterior AMI & 3.70 & $2.93-5.41$ & .001 \\
Preoperative LVEDD $\geq 70 \mathrm{~mm}$ & 3.91 & $2.65-5.22$ & .001 \\
CD at discharge $\geq 0.5 \mathrm{~cm}$ & 11.9 & $5.91-21.34$ & .0001 \\
\hline
\end{tabular}

ICMR, Ischemic chronic mitral regurgitation; $A M I$, acute myocardial infarction; $L V E D D$, left ventricular end-diastolic diameter; $C D$, coaptation depth. 

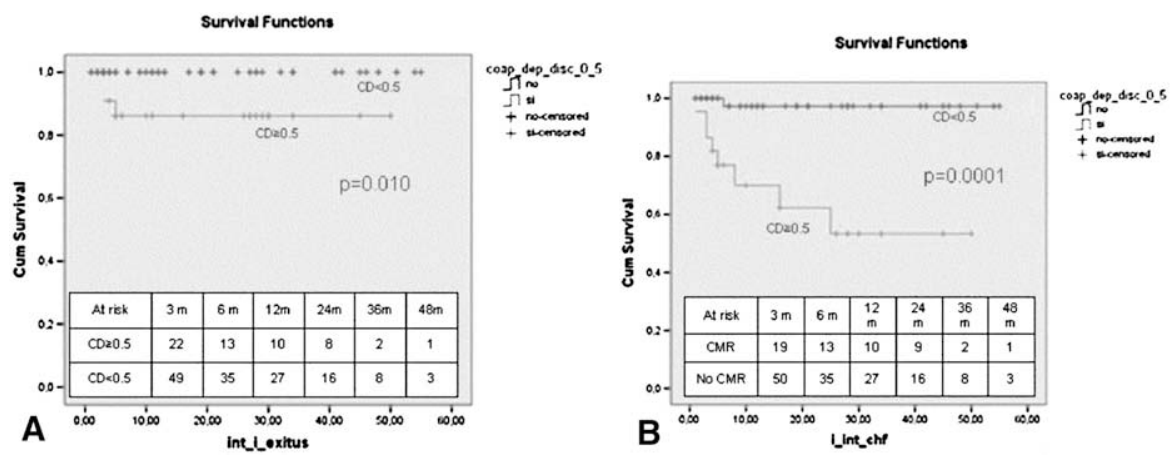

FIGURE 3. Survival (A) and freedom from congestive heart failure (B) between patients with coaptation depth $\geq 0.5 \mathrm{~cm}$ at discharge and those with coaptation depth $<0.5 \mathrm{~cm}$ at discharge.

the progressive ventricular dilation and the ongoing cardiomyopathy act for late recurrences during the follow-up. ${ }^{5-8,13}$ All these factors have led surgeons to identify the predictors for recurrence of ICMR despite MRA. Most of these predictors are preoperative characteristics, such as CD $>10 \mathrm{~mm},{ }^{8}$ preoperative LVEDD $>65 \mathrm{~mm},{ }^{14}$ short posterior tethering, ${ }^{15}$ and interpapillary distance $>20 \mathrm{~mm}^{7}$ However, literature lacks early predictors of ICMR recurrence following MRA. Our data confirm previous reports ${ }^{14}$ showing preoperative enlarged LVEDD ( $\geq 70 \mathrm{~mm}$ in our experience) to predict MRA failure. Accordingly, preoperative LVEDD $\geq 70 \mathrm{~mm}$ correlated with lower 2-year freedom from CHF and worsened NYHA class. Moreover, we further found that $C D \geq 0.5$ $\mathrm{cm}$ at discharge predicted the recurrence of ICMR. Therefore, the identification of a $\mathrm{CD} \geq 0.5 \mathrm{~cm}$ may help early detection of a higher risk for recurrences. This finding therefore should lead physicians to be more aggressive with medical therapy, to be closer on patient's follow-up, or to consider different strategies. ${ }^{5}$ In our experience, $\mathrm{CD} \geq 0.5 \mathrm{~cm}$ is the most powerful predictor of recurrent ICMR despite MRA. Furthermore, compared with the preoperative predictors of ICMR already reported, ${ }^{7,8,14,15} \mathrm{CD}$ at discharge is certainly related to the preoperative degree of postischemic left ventricular sphericalization, ${ }^{1,2,4}$ but it may also reflect a slightly less stringent septolateral cinching during the surgical time. ${ }^{16}$ Furthermore, dichotomizing patients on the basis of their discharge $\mathrm{CD}$, we found that those with $\mathrm{CD} \geq 0.5 \mathrm{~cm}$ had poorer survival and lower 2-year freedom from CHF, with worsening NYHA class and progressive decompensation. Accordingly, they needed also higher doses of daily furosemide.

It is well known that patients with ICMR have a worse natural history: the SAVE study demonstrated that patients with mild ICMR had an increased risk of cardiovascular mortality ( $29 \%$ vs $12 \%)$ and heart failure $(24 \%$ vs $16 \%)$ at 3.5 years after AMI compared with patients without ICMR. Adjustment for differences in baseline characteristics revealed that mild to moderate ICMR strongly predicted midterm mortality. ${ }^{17}$ Therefore, it was not surprising that patients with recurrent ICMR showed lower 2-year freedom from death, CHF, and redo mitral surgery, together with

TABLE 5. Recovery of NYHA class and need for daily diuretic dose in patients with and without preoperative LVEDD $\geq 70 \mathrm{~mm}$ or with and without $\mathrm{CD} \geq 0.5 \mathrm{~cm}$ at discharge

\begin{tabular}{|c|c|c|c|c|c|c|}
\hline & Preoperative NYHA & Discharge NYHA & 6-mo NYHA & Follow-up NYHA & $P^{*}$ & $\boldsymbol{P} \dagger$ \\
\hline Preoperative LVEDD $\geq 70 \mathrm{~mm}$ & $3.6 \pm 0.5$ & $1.8 \pm 0.4$ & $1.9 \pm 0.6$ & $2.4 \pm 1.0$ & .005 & .0001 \\
\hline \multirow[t]{2}{*}{ Preoperative LVEDD $<70 \mathrm{~mm}$} & $3.3 \pm 0.6$ & $1.6 \pm 0.5$ & $1.5 \pm 0.6$ & $1.1 \pm 0.5$ & .0001 & \\
\hline & $\begin{array}{l}\text { Preoperative daily } \\
\text { furosemide }(\mathbf{m g})\end{array}$ & $\begin{array}{l}\text { Discharge daily } \\
\text { furosemide (mg) }\end{array}$ & $\begin{array}{l}\text { 6-mo daily } \\
\text { furosemide (mg) }\end{array}$ & $\begin{array}{l}\text { Follow-up daily } \\
\text { furosemide (mg) }\end{array}$ & $P^{*}$ & $\boldsymbol{P} \dagger$ \\
\hline Preoperative LVEDD $\geq 70 \mathrm{~mm}$ & $93.9 \pm 51.6$ & $37.5 \pm 16.8$ & $53.1 \pm 32.9$ & $72.9 \pm 37.6$ & .007 & .0001 \\
\hline \multirow[t]{2}{*}{ Preoperative LVEDD $<70 \mathrm{~mm}$} & $73.9 \pm 25.7$ & $30.9 \pm 11.7$ & $24.2 \pm 13.8$ & $20.9 \pm 20.7$ & .0001 & \\
\hline & Preoperative NYHA & Discharge NYHA & 6-mo NYHA & Follow-up NYHA & $P^{*}$ & $\boldsymbol{P} \dagger$ \\
\hline Discharge $\mathrm{CD} \geq 0.5 \mathrm{~cm}$ & $3.6 \pm 0.5$ & $1.8 \pm 0.4$ & $1.9 \pm 0.7$ & $2.3 \pm 0.9$ & .002 & .0001 \\
\hline Discharge $\mathrm{CD}<0.5 \mathrm{~cm}$ & $3.3 \pm 0.5$ & $1.6 \pm 0.5$ & $1.4 \pm 0.4$ & $1.1 \pm 0.4$ & .0001 & \\
\hline
\end{tabular}

\begin{tabular}{lccccc} 
& $\begin{array}{c}\text { Preoperative daily } \\
\text { furosemide (mg) }\end{array}$ & $\begin{array}{c}\text { Discharge daily } \\
\text { furosemide (mg) }\end{array}$ & $\begin{array}{l}\text { 6-mo daily } \\
\text { furosemide (mg) }\end{array}$ & $\begin{array}{l}\text { Follow-up daily } \\
\text { furosemide (mg) }\end{array}$ & \multicolumn{1}{c}{$\boldsymbol{P}^{*}$} \\
\hline Discharge CD $\geq 0.5 \mathrm{~cm}$ & $91.6 \pm 49.7$ & $38.3 \pm 15.9$ & $55.0 \pm 30.2$ & $72.5 \pm 37.2$ & .001 \\
Discharge CD $<0.5 \mathrm{~cm}$ & $74.4 \pm 25.3$ & $30.2 \pm 11.3$ & $21.5 \pm 8.7$ & .0001 \\
\hline
\end{tabular}

$C D$, Coaptation depth; $L V E D D$, left ventricular end-diastolic diameter; $N Y H A$, New York Heart Association. *Statistical probability within group; †statistical probability between groups. 
a progressive worsening of their NYHA class and need for diuretics, when compared with patients with recurrent ICMR. Given the higher prevalence of recurrent ICMR when high $\mathrm{CD}$ is found, patients with discharge $\mathrm{CD} \geq 0.5$ share the same outcome. Our findings correlated with those of De Bonis $^{18}$ showing a significantly worse NYHA class when ICMR recurred and those of Gelsomino, ${ }^{6}$ who found higher NYHA class and reoperation rate when MRA failed. Accordingly, Braun and colleagues ${ }^{14}$ showed that recurrent ICMR reduces survival without ventricular reverse remodeling.

When echocardiographic results are considered, we found a different fate of the left ventricle, based on the midterm efficacy of MRA. Failed MRA resulted in recurrent ICMR and therefore did not correlate with any left ventricular reverse remodeling. On the contrary, successful MRA cured ICMR, correlating with reverse remodeling of LVEDD, LVESD, LVMi, together with improved LVEF and right ventricular function, as demonstrated by the amelioration of TI grade and PAP. Therefore, it was not surprising that patients with recurrent ICMR showed worsening functional class and a need for higher daily doses of diuretics. These data agree with the majority of the literature reports, all showing worsened survival and functional deterioration when ICMR reccurs. ${ }^{5-8,11-13}$ In fact, it is noteworthy that Bolling and associates ${ }^{19}$ first reported NYHA class amelioration following MRA in old ischemic patients in the early 1990s. Since then, recurrences of mitral regurgitation dramatically impacted follow-up survival, despite continuous improvements of the surgical and medical therapies. ${ }^{20} \mathrm{Bax}$ and coworkers $^{21}$ already demonstrated that effective MRA induced left ventricular and left atrial reverse remodeling. Our data confirm those of Bax and colleagues only when left ventricular remodeling was considered. However, we did not found reverse remodeling of the left atrial chamber, even in patients without recurrent ICMR. These results could possibly be related to the higher mean transmitral gradients of patients with successful MRA compared with those with MRA failure. Accordingly, a recent report from Magne and associates $^{22}$ reported MRA to have the potential to induce variable degrees of iatrogenic functional mitral stenosis. Certainly, more studies addressing such topics are needed to clarify the potential deleterious effects of MRA. Finally, we found that combined anterior + posterior myocardial infarction also predicted midterm failure of MRA. It has been established that evolution of ICMR involves complex interactions between leaflets, annulus, chordate tendineae, papillary muscles, and so on. ${ }^{1,2,11}$ Complex phenomena contributed to ICMR, ranging from posterior papillary muscle dislodgement, anterior and posterior annular dilation, loss of the saddle shape and systodiastolic movements of the annular plane, chordal and papillary muscle tethering action on both leaflets, and so on. ${ }^{23}$ Lateral displacement of the posterior papillary muscle appears to play a major role in the development of ICMR following inferior AMI. ${ }^{23}$ Small infarcts in the area of posterior papillary muscle can lead to significant ICMR. ${ }^{24}$ However, from a functional point of view, it has been demonstrated that the degree of functional mitral regurgitation is determined by mitral tenting, which is directly related to the displacement of the papillary muscles. ${ }^{25}$ In particular, not only posterior but also apical displacements of both anterior and posterior papillary muscles enhance ICMR. ${ }^{11,25}$ Similarly, left ventricular distortion and remodeling after an anterior infarction displace papillary muscles toward the apex, resulting in apical mitral tethering and restriction of coaptation during systole. ${ }^{26}$ Moreover, left ventricular restoration in patients with dyskinetic or aneurysmatic left ventricles may often restore the mitral competence. ${ }^{26}$ Therefore, it is not surprising that patients with either anterior or posterior AMI during their lives had extended and complex preoperative ventricular remodeling. In these patients, further surgical strategies other than MRA should be considered to completely address the complex pathogenesis underlying their ICMR.

Therefore, we conclude that MRA failure is responsible for follow-up mortality and CHF and correlates with the absence of reverse remodeling of the ventricular chamber. Prognosis of patients having MRA in ICMR is good, as long as a low postoperative $\mathrm{CD}$ is achieved. Patients with preoperative significant left ventricular dilation exceeding $70 \mathrm{~mm}$ of LVEDD or with extensive preoperative left ventricular remodeling because of multiple anterior and posterior infarcts should be considered for complementary surgical strategies.

\section{Limitations of the Study}

The main limitation of the study is the small sample size of patients enrolled. This results from the single-center design of the study, which, on the other hand, guarantees uniformity of the surgical technique and perioperative care. The $100 \%$ follow-up is also a strength. Another limitation is the relatively low number of recurrent ICMR during the follow-up, which may limit the efficacy of a multivariable analysis, where an accepted rule of thumbis to include 1 variable forconsideration for every 10 outcomes of interest. However, we have tried to limit the risk of an overfitted model by including in the logistic regression only those variables $(\mathrm{n}=8)$ with a highly significant correlation $(P<.0001)$ with recurrent ICMR. In this way, the multivariable model proved reliable, given a c-statistic of 0.950 and a Hosmer-Lemeshow's goodness-of-fit $P$ of .646.

\section{References}

1. Komeda M, Glasson JR, Bolger AF, et al. Geometric determinants of ischemic mitral regurgitation. Circulation. 1997;96(9 Suppl):II128-33.

2. Otsuji Y, Handschumacher MD, Liel-Cohen N, et al. Mechanism of ischemic mitral regurgitation with segmental left ventricular dysfunction: three-dimensional echocardiographic studies in models of acute and chronic progressive regurgitation. J Am Coll Cardiol. 2001;37:641-8.

3. Yiu SF, Enriquez-Sarano M, Tribouilloy C, et al. Determinants of the degree of functional mitral regurgitation in patients with systolic left ventricular dysfunction: a quantitative clinical study. Circulation. 2000;102:1400-6.

4. Srichai MB, Grimm RA, Stillman AE, et al. Ischemic mitral regurgitation: impact of LV and MV in patients with left ventricular systolic dysfunction. Ann Thorac Surg. 2005;80:170-8. 
5. Braun J, van de Veire NR, Klautz RJM, et al. Restrictive mitral annuloplasty cures ischemic mitral regurgitation and heart failure. Ann Thorac Surg. 2008; 85:430-7.

6. Gelsomino S, Lorusso R, Capecchi I, et al. Left ventricular reverse remodeling after undersized mitral ring annuloplasty in patients with ischemic regurgitation. Ann Thorac Surg. 2008;85:1319-30.

7. Roshanali F, Mandegar MH, Yousefnia MA, et al. A prospective study of predicting factors in ischemic mitral regurgitation recurrence after ring annuloplasty. Ann Thorac Surg. 2007;84:745-9.

8. Calafiore AM, Di Mauro M, Gallina S, et al. MV surgery for chronic ischemic mitral regurgitation. Ann Thorac Surg. 2004;77:1989-7.

9. Hung J, Papakostas L, Tahta SA, et al. Mechanism of recurrent ischemic mitral regurgitation after annuloplasty. Continued LV remodelling as a moving target. Circulation. 2004;110(11 Suppl. 1):II85-90.

10. Onorati F, Cristodoro L, Caroleo S, Esposito A, Amantea B, Santangelo E, Renzulli A. Troponin I and lactate from coronary sinus predict cardiac complications after myocardial revascularization. Ann Thorac Surg. 2007;83: 1016-23.

11. Borger MA, Alam A, Murphy PM, et al. Chronic ischemic mitral regurgitation: repair, replace or rethink? Ann Thorac Surg. 2006;81:1153-61.

12. Tahta SA, Oury JH, Maxwell JM, et al. Outcome after MV repair for functional ischemic mitral regurgitation. J Heart Valve Dis. 2002;11:11-8.

13. McGee EC, Gillinov AM, Blackstone EH, et al. Recurrent mitral regurgitation after annuloplasty for functional ischemic mitral regurgitation. J Thorac Cardiovasc Surg. 2004;128:916-24.

14. Braun J, Bax JJ, Versteegh MI, et al. Preoperative left ventricular dimensions predict reverse remodeling in restrictive mitral annuloplasty in ischemic mitral regurgitation. Eur J Cardiothorac Surg. 2005;27:847-53.

15. Serri K, Bouchard D, Demers P, et al. Is a good perioperative echocardiographic result predictive of durability in ischemic MV repair? J Thorac Cardiovasc Surg. 2006;131:565-73.

APPENDIX. Perioperative variables analyzed as univariate predictors of ICMR recurrence

\begin{tabular}{|c|c|c|c|}
\hline Variables & $\begin{array}{c}\text { ICMR } \\
\text { recurrence } \\
\end{array}$ & $\begin{array}{l}\text { No ICMR } \\
\text { recurrence } \\
\end{array}$ & $\boldsymbol{P}$ \\
\hline Age & $69.9 \pm 2.8$ & $70.9 \pm 4.0$ & .711 \\
\hline EUROscore & $8.1 \pm 1.2$ & $8.3 \pm 1.6$ & .522 \\
\hline Sex (male) & $13(65.0 \%)$ & $41(71.9 \%)$ & .376 \\
\hline Diabetes & $16(80.0 \%)$ & $20(35.1 \%)$ & .001 \\
\hline Hypertension & $15(75.0 \%)$ & $39(68.4 \%)$ & .401 \\
\hline Dyslipidemia & $5(25.0 \%)$ & $15(26.3 \%)$ & .580 \\
\hline COPD & $8(40.0 \%)$ & $17(29.8 \%)$ & .285 \\
\hline UA/NSTEMI & $10(50.0 \%)$ & $21(36.8 \%)$ & .221 \\
\hline STEMI & $0(0 \%)$ & $1(1.8 \%)$ & .740 \\
\hline Previous AMI & $11(55.0 \%)$ & $39(68.4 \%)$ & .208 \\
\hline Recent AMI & $17(85.0 \%)$ & $25(43.9 \%)$ & .001 \\
\hline Anterior AMI & $5(25.0 \%)$ & $5(8.8 \%)$ & .075 \\
\hline Posterior AMI & $6(30.0 \%)$ & $51(89.4 \%)$ & .0001 \\
\hline Anterior + posterior AMI & $9(45.0 \%)$ & $2(3.6 \%)$ & .0001 \\
\hline LMSD & $10(50.0 \%)$ & $16(27.6 \%)$ & .061 \\
\hline Preoperative NYHA & $3.7 \pm 0.4$ & $3.2 \pm 0.5$ & .0001 \\
\hline Preoperative diuretics & $92.2 \pm 45.7$ & $71.5 \pm 23.4$ & .022 \\
\hline Preoperative ICMR & $3.5 \pm 0.6$ & $3.4 \pm 0.5$ & .037 \\
\hline Preoperative TI & $2.1 \pm 0.6$ & $1.9 \pm 0.5$ & .441 \\
\hline Preoperative PAP & $45.0 \pm 8.4$ & $38.1 \pm 6.4$ & .047 \\
\hline Preoperative LAD & $46.1 \pm 5.7$ & $45.6 \pm 3.4$ & .202 \\
\hline Preoperative LVEDD & $67.1 \pm 8.2$ & $63.9 \pm 4.9$ & .008 \\
\hline $\begin{array}{l}\text { Preoperative LVEDD } \\
\quad>70 \mathrm{~mm}\end{array}$ & $14(73.7 \%)$ & $4(7.0 \%)$ & .0001 \\
\hline Preoperative LVESD & $55.3 \pm 13.5$ & $54.4 \pm 6.6$ & .028 \\
\hline Preoperative LVMi & $145.3 \pm 19.2$ & $138.7 \pm 20.2$ & .069 \\
\hline Preoperative LVEF & $38.1 \pm 8.7$ & $40.1 \pm 6.8$ & .174 \\
\hline
\end{tabular}

16. Tibayan FA, Rodriguez F, Langer F, et al. Does septal-lateral annular cinching work for chronic ischemic mitral regurgitation? J Thorac Cardiovasc Surg. 2004; 127:654-63.

17. Lamas GA, Mitchell GF, Flaker GC, et al. Clinical significance of mitral regurgitation after acute myocardial infarction. Survival and Ventricular Enlargement Investigators. Circulation. 1997;96:827-33.

18. De Bonis M, Lapenna E, Verzini A, et al. Recurrence of mitral regurgitation parallels the absence of left ventricular reverse remodeling after mitral valve repair in advanced dilated cardiomyopathy. Ann Thorac Surg. 2008;85:932-9.

19. Bolling SF, Deeb GM, Bach DS. MV reconstruction in elderly, ischemic patients. Chest. 1996;109:35-40.

20. Crabtree TD, Bailey MS, Moon MR, et al. Recurrent mitral regurgitation and risk factors for early and late mortality after MV repair for functional ischemic mitral regurgitation. Ann Thorac Surg. 2008;85:1537-42.

21. Bax JJ, Braun J, Somer ST, et al. Restrictive annuloplasty and coronary revascularization in ischemic mitral regurgitation results in reverse left ventricular remodeling. Circulation. 2004;110(Suppl 2). II-104-8.

22. Magne J, Senechal M, Mathieu P, et al. Restrictive annuloplasty for ischemic mitral regurgitation may induce functional mitral stenosis. J Am Coll Cardiol. 2008;51:1692-701.

23. Szeto WY, Gorman RC, Gorman JH III, et al. Ischemic mitral regurgitation. In: Cohn LH, ed. Cardiac surgery in the adult. New York: McGraw-Hill; 2008:785-802.

24. Gorman JH III, Gorman RC, Jackson BM, et al. Annuloplasty ring selection for chronic ischemic mitral regurgitation: lessons from the ovine model. Ann Thorac Surg. 2003;76:1556.

25. Yiu SF, Enriquez-Sarano M, Tribouilloy C, et al. Determinants of the degree of functional mitral regurgitation in patients with systolic left ventricular dysfunction. a quantitative clinical study. Circulation. 2000;102:1400-6.

26. Di Donato M, Castelvecchio S, Brankovic J, et al. Effectiveness of surgical ventricular restoration in patients with dilated ischemic cardiomyopathy and unrepaired mild mitral regurgitation. J Thorac Cardiovasc Surg. 2007;134:1548-53.

\section{APPENDIX. Continued}

\begin{tabular}{|c|c|c|c|}
\hline Variables & $\begin{array}{c}\text { ICMR } \\
\text { recurrence }\end{array}$ & $\begin{array}{l}\text { No ICMR } \\
\text { recurrence }\end{array}$ & $\boldsymbol{P}$ \\
\hline Preoperative CD & $1.3 \pm 0.2$ & $1.3 \pm 0.2$ & .501 \\
\hline Preoperative transmitral $\Delta \mathrm{p}$ & $0.9 \pm 0.9$ & $0.9 \pm 0.8$ & .693 \\
\hline No. CABG & $2.0 \pm 1.1$ & $2.5 \pm 0.9$ & .040 \\
\hline Tricuspid plasty & $3(15.0 \%)$ & $13(22.8 \%)$ & .348 \\
\hline ACC time (min) & $73.4 \pm 4.8$ & $73.7 \pm 4.5$ & .832 \\
\hline CPB time (min) & $138.7 \pm 15.7$ & $136.3 \pm 10.8$ & .450 \\
\hline Discharge NYHA & $1.8 \pm 0.3$ & $1.5 \pm 0.5$ & .031 \\
\hline Discharge diuretics & $42.3 \pm 13.6$ & $25.5 \pm 14.2$ & .004 \\
\hline Discharge ICMR & $1.2 \pm 0.4$ & $0.7 \pm 0.4$ & .0001 \\
\hline Discharge TI & $1.3 \pm 0.5$ & $1.1 \pm 0.2$ & .533 \\
\hline Discharge PAP & $36.6 \pm 7.9$ & $31.3 \pm 5.9$ & .025 \\
\hline Discharge LAD & $46.3 \pm 5.9$ & $45.5 \pm 3.2$ & .063 \\
\hline Discharge LVEDD & $67.0 \pm 8.0$ & $62.4 \pm 4.9$ & .001 \\
\hline Discharge LVESD & $55.3 \pm 13.0$ & $49.6 \pm 6.6$ & .010 \\
\hline Discharge LVMi & $145.4 \pm 19.5$ & $138.5 \pm 19.9$ & .050 \\
\hline Discharge LVEF & $35.2 \pm 8.0$ & $37.8 \pm 6.9$ & .048 \\
\hline Discharge CD & $0.7 \pm 0.3$ & $0.4 \pm 0.2$ & .0001 \\
\hline Discharge $C D \geq 0.5 \mathrm{~cm}$ & $18(90.0 \%)$ & $3(5.3 \%)$ & .0001 \\
\hline Discharge transmitral $\Delta \mathrm{p}$ & $4.7 \pm 0.9$ & $5.6 \pm 1.3$ & .0001 \\
\hline Redo mitral surgery & $2(10.0 \%)$ & $0(0 \%)$ & .065 \\
\hline Re-revascularization & $0(0 \%)$ & $1(1.8 \%)$ & .740 \\
\hline
\end{tabular}

COPD, Chronic obstructive pulmonary disease; EuroSCORE, European System for Cardiac Operative Risk Evaluation; UA/NSTEMI, unstable angina/non-ST elevation myocardial infarction; STEMI, ST elevation myocardial infarction; $A M I$, acute myocardial infarction; $L M S D$, left main stem disease; $N Y H A$, New York Heart Association; $I C M R$, chronic mitral regurgitation; TI, tricuspid insufficiency; PAP, systolic pulmonary arterial pressure; $L A D$, left atrial diameter; $L V E D D$, left ventricular end-diastolic diameter; $L V E S D$, left ventricular end-systolic diameter; $L V M i$, indeed left ventricular mass; $L V E F$, left ventricular ejection fraction; $C D$, coaptation depth; $C A B G$, coronary artery bypass grafting; $A C C$, aortic crossclamp; $C P B$, cardiopulmonary bypass. 